\title{
THE EFFECTS OF DIFFERENT MUTAGENS ON SELF- INCOMPATIBILITY IN NICOTIANA ALATA LINK AND OTTO
}

\section{ACUTE IRRADIATIONS WITH X-RAYS AND FAST NEUTRONS*}

\author{
A. J. G. VAN GASTEL \\ Assoc. Euratom-ITAL, P.O. Box 48, Wageningen, The Netherlands \\ and \\ D. DE NETTANCOURT \\ Service de Biologie, DG XII, C.C.E., Bruxelles, Belgique
}

Received 5.viii.74

\begin{abstract}
SUMMARY
Pollen mother cells of Nicotiana alata were exposed to acute doses of X-rays or fast neutrons and, at anthesis, the pollen produced was used to pollinate unirradiated plants of the same clone. The results indicate that fast neutrons are slightly more effective than X-rays for inducing self-compatible pollenpart mutations but that neither fast neutrons nor X-rays have the capacity to generate new self-incompatibility alleles. An unexpectedly high fraction of the self-compatibility mutations induced does not display the centric fragment which usually characterises such mutations. The ratio of fragment to non-fragment self-compatibility mutations of fast neutrons is identical to that of X-rays. The possible use of permanent self-compatibility mutations for production of $\mathrm{F}_{1}$ hybrid seed is discussed.
\end{abstract}

\section{INTRODUCTION}

THE $S$-locus in a monofactorial gametophytic system of self-incompatibility constitutes a unique material for analysing, in higher organisms, the mutation spectrum of a single gene complex (van Gastel and de Nettancourt, 1974). After mutagenic treatment, three types of genetic changes (generation of a new $S$-allele, self-compatibility mutations associated with the presence of a centric fragment, self-compatibility mutations not associated with a centric fragment) may theoretically be expected to express themselves in the pollen grains (Lewis, 1946, 1948, 1949, 1951; Pandey, 1956, 1965, 1967b, 1969c, $1970 a, 1970 b$; Brewbaker and Shapiro, 1959; Brewbaker and Emery, 1960; Brewbaker and Natarajan, 1960; Hoffmann, 1971; de Nettancourt et al., 1971; Hogenboom, 1972). These mutations are automatically selected after selfing and sorted out with relative ease in the next generation.

The mutagenic analyses carried out so far have shown that X-rays (Lewis, 1949; Pandey, 1967b) are considerably more efficient than chronic $y$ irradiations (van Gastel and de Nettancourt, 1974) for inducing selfcompatibility mutations, but that neither acute nor chronic exposure to $\mathrm{X}$-rays or $\gamma$-rays appeared to have the capacity to reconstruct, within the $S$-locus, a new functional self-incompatibility allele.

Ionising radiation, in other words, is a useful agent for transforming a self-incompatible plant into a self-compatible one, but seems to be of no utility as far as the generation of new specificities is concerned.

* This contribution is No. 1060 from the Biology Division of the European Communities. 
As a logical continuation to these investigations, the present study aimed at comparing the mutation spectrum induced by X-rays at the $S$-locus to that of fast neutrons, a class of mutagens with a high RBE (Contant et al., 1971) and a specific mutagenicity (Lundqvist and von Wettstein, 1962).

\section{MATERIAL AND METHODS}

(i) Test-species and growing conditions

The test material chosen for these experiments was the same $S_{2} S_{3}$ clone of Nicotiana alata Link and Otto which had been used in experiments with chronic irradiation (van Gastel and de Nettancourt, 1974) and for which considerable genetical analyses have been carried out (Pandey, 1964, 1967a, $1969 a, 1969 b, 1970 a)$. Plants were kept in controlled climate rooms ( 16 hours day, $13,000 \mathrm{Lux}, 23^{\circ} \mathrm{C}$; 8 hours night, $17^{\circ} \mathrm{C}$; relative humidity 60-70 per cent).

\section{(ii) Irradiation sources}

$\mathrm{X}$-irradiation was applied at a dose rate of $20 \mathrm{rad} / \mathrm{minute}$, by a Philips $250 / 25$ deep therapy apparatus, operating at $250 \mathrm{kV}$ and $15 \mathrm{~mA}$, with an additional $0.5 \mathrm{Cu}, 1.0 \mathrm{Al}$ filter.

The source of fast neutrons was the BARN (Biological Agricultural Reactor Netherlands). Absorbed doses were calculated from the equation $D_{p}=1.25 \times D_{N(\mathrm{CH})}$, where $D_{p}$ is the absorbed dose in rads by the irradiated plant tissue, 1.25 is the correction factor taking into account the elementary composition of flower buds in the related species Lycopersicon esculentum (Contant et al., 1971) and $D_{N(C H)}$ is the measured dose in ethylene (in rads). The $\gamma$-contamination of the fast neutron beam did not exceed 10 per cent of the total absorbed dose. Plants were always placed at the same distance from the source. The exposure time was 33 minutes.

\section{(iii) Stage of treatment and radiation doses}

Because $S$-mutations induced after the tetrad stage cannot express themselves in the pollen, all irradiations were carried out on buds with pollen mother cells (PMC) at the meiotic stage, the most sensitive stage in the anthers (Lewis, 1949).

In order to compare the mutagenic effects of X-rays and fast neutrons at similar levels of induced pollen sterility, doses had been determined, in a preliminary experiment, which led to 20,50 and 75 per cent of pollen sterility respectivily. Hence the following doses were chosen: X-rays, 300, 600 and $825 \mathrm{rad}$; fast neutrons, 50,175 and $300 \mathrm{rad}$.

\section{(iv) Pollination procedures and detection of radiation effects}

A total of 167 and 99 flowering plants, respectively, were submitted to $\mathrm{X}$-rays and fast neutrons. Mature pollen from each of the flowers which had been in meiosis at the time of irradiation was collected and deposited on the stigmas of two unirradiated flowers from the same clone $\left(S_{2} S_{3}\right)$. To prevent abscission of flowers or of young capsules and to induce swelling of the ovary, 1 per cent naphthalene acetamide in lanolin was applied 
around the calyx of the flowers immediately after pollination (Pandey, 1967b). After fruit harvest, the seeds present in each fruit (or a fraction of them) were sown and the resulting plants self-pollinated and test-crossed to the original mother clone and to homozygous tester stocks $\left(S_{2} S_{2}\right.$ and $\left.S_{3} S_{3}\right)$. The same procedure was carried out with the 65 control plants.

\section{(v) Estimation of mutation rates}

A factor which, a priori, must be taken into consideration for the calculation of the mutation rates is the time of $S$-gene mutation during microsporogenesis. Since irradiation was applied to meiotic buds, more than one self-compatible pollen grain may have resulted, in a number of cases, from a single mutational event. In order to overcome this complication, the mutation rates were first calculated in two different manners:

By estimating the number of self-compatible individuals in the progenies per pollination. This assumes that each mutation gives rise to only one mutant and, therefore, probably represents an overestimate of the mutation rate.

By estimating the number of fruits containing mutated seeds per pollination. This assumes that a cluster of mutant seeds in one fruit stems from only one mutation and probably represents an underestimate of the mutation rate.

As the results obtained in the present study showed that most mutants appeared in different progenies (see Results and fig. 1), it became obvious that the best method for estimating mutation frequencies was the one which took into account the number of self-compatible individuals per pollination. Accordingly the values calculated through this method are given and considered for discussion.

As the number of $S$-mutants detected in progeny tests only represents a fraction of the number of mutations induced, an attempt was also made to determine the total number of mutations by assuming that all mutations occurred independently of other damage leading to sterility and lethality. This estimate of all induced $S$-mutations was obtained by means of corrections which took into account the number of $S$-mutations supposedly eliminated through a casual association with pollen abortion, failure of seed germination or flowering inhibition. However, an analysis of the results at the end of our experiments showed that these corrections did not modify the general trends expressed by the uncorrected data and were therefore superfluous. They are consequently omitted in the present article, which only deals with the uncorrected values.

\section{(vi) Cytological techniques}

Estimates of pollen fertility and chromosome analyses were carried out with the help of techniques described earlier (van Gastel and de Nettancourt, 1974).

\section{Results}

\section{(i) Pollen stainability}

A significant decrease in pollen fertility with increasing doses was observed after X-rays and after fast neutrons (table 1). 

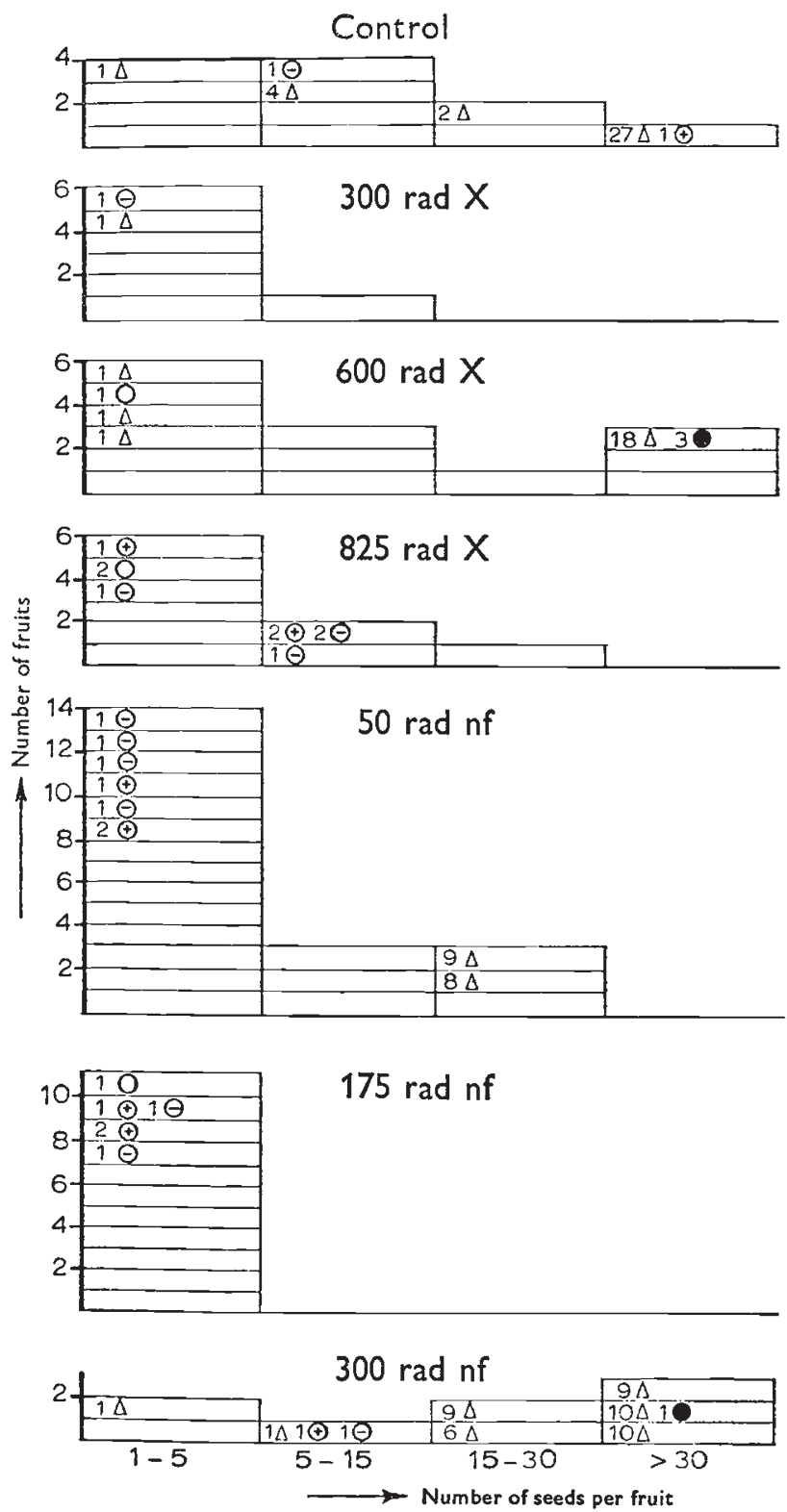

FIG. 1.-Distribution of seed set and distribution of mutated and non-mutated individuals

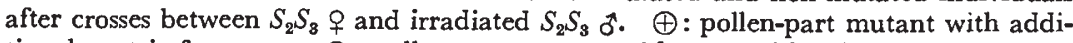
tional centric fragment. $\ominus$ : pollen-part mutant without additional centric fragment. $\bigcirc$ : pollen-part mutant not analysed cytologically. $\bullet$ : partial stylar-part mutant. $\triangle$ : non-mutated plant. 
TABLE 1

Consequences of pollinations with irradiated and unirradiated pollen on fertility relationships and frequency of S-mutations

\begin{tabular}{|c|c|c|c|c|c|c|c|}
\hline \multicolumn{2}{|l|}{ Treatment } & \multicolumn{3}{|c|}{$\mathrm{X}$-rays } & \multicolumn{3}{|c|}{ Fast neutrons } \\
\hline Dose (in rads) & Control & 300 & 600 & 825 & 50 & 175 & 300 \\
\hline$\%$ of fertile pollen & $92 \cdot 0$ & $81 \cdot 9$ & $63 \cdot 2$ & $51 \cdot 6$ & $75 \cdot 6$ & $56 \cdot 5$ & $48 \cdot 0$ \\
\hline No. of pollinations & 487 & 572 & 472 & 420 & 257 & 247 & 157 \\
\hline No. of fruits & 11 & 7 & 13 & 9 & 20 & 11 & 8 \\
\hline No. of seeds & 154 & 22 & 391 & 54 & 217 & 35 & 311 \\
\hline No. of seeds sown & 129 & 22 & 247 & 54 & 107 & 35 & 110 \\
\hline No. of seeds germinated & 53 & 3 & 36 & 10 & 38 & 13 & 59 \\
\hline No. of plants tested & 36 & 2 & 25 & 9 & 24 & 6 & 49 \\
\hline No. of pollen-part mutants & 2 & 1 & 1 & 9 & 7 & 6 & 2 \\
\hline No. of stylar-part mutants & - & - & 3 & - & - & - & $\overrightarrow{1}$ \\
\hline
\end{tabular}

(ii) Fruit and seed set after crosses between irradiated pollen donors and unirradiated recipients $\left(\mathrm{S}_{2} \mathrm{~S}_{3}\right.$ 古 $\times \mathrm{S}_{2} \mathrm{~S}_{3}$ ठ $)$

The effects of irradiation on fruit- and seed yield are presented in table 2. $\mathrm{X}$-rays had practically no effect on the number of seeded fruits per pollination. A clear increase, however, was obtained after fast neutron irradiation where the number of fruits per pollination was about two times higher than in the control series.

\section{TABLE 2}

Effects on fruit yield, seed yield and mutation rates after cross-pollinations between $\mathrm{S}_{2} \mathrm{~S}_{3}$ 우 and irradiated $\mathrm{S}_{2} \mathrm{~S}_{3}$ oै

\begin{tabular}{|c|c|c|c|c|c|}
\hline & \multirow[b]{2}{*}{$\begin{array}{l}\text { Dose } \\
(\mathrm{rad})\end{array}$} & \multirow[b]{2}{*}{$\begin{array}{l}\text { No. of seeded } \\
\text { fruits per } \\
\text { pollination }\end{array}$} & \multirow[b]{2}{*}{$\begin{array}{c}\text { No. of seeds } \\
\text { per } \\
\text { pollination }\end{array}$} & \multicolumn{2}{|c|}{$\begin{array}{l}\text { No. of self-compatible } \\
\text { individuals per pollination* }\end{array}$} \\
\hline & & & & $\begin{array}{l}\text { Pollen-part } \\
\text { mutants }\end{array}$ & $\begin{array}{l}\text { Stylar-part } \\
\text { mutants }\end{array}$ \\
\hline itrol & - & 0.023 & 0.32 & 0.005 & - \\
\hline ays & $\begin{array}{l}300 \\
600 \\
825\end{array}$ & $\begin{array}{l}0.012 \\
0 \cdot 028 \\
0.021\end{array}$ & $\begin{array}{l}0 \cdot 04 \\
0.83 \\
0.13\end{array}$ & $\begin{array}{l}0.002 \\
0.003 \\
0.021\end{array}$ & $\overline{0.010}$ \\
\hline Eutrol & $\begin{array}{r}50 \\
175 \\
300\end{array}$ & $\begin{array}{l}0 \cdot 078 \\
0 \cdot 045 \\
0 \cdot 051\end{array}$ & $\begin{array}{l}0 \cdot 84 \\
0 \cdot 14 \\
1 \cdot 98\end{array}$ & $\begin{array}{l}0.055 \\
0.024 \\
0.036\end{array}$ & $\frac{-}{0 \cdot 018}$ \\
\hline
\end{tabular}

* The number of mutants obtained are corrected for the fraction of seeds sown (see table 1).

With regard to seed set no clear dose-response relationship could be established as only certain doses resulted in a sharp increase in seed production.

\section{(iii) Progeny testing for S-mutations}

The test-crosses which were carried out for detecting $S$-mutants among the progenies revealed that 32 individuals (14 in the X-ray series, 16 after fast neutrons and 2 in the control) were self-compatible (table 3 ). As can be seen in fig. 1, the majority of the mutants were detected in different progenies and, as a general rule, arose from fruits which contained only few 
seeds. In the few cases where more than one mutant was detected in the same fruit the mutants often belonged to different classes (with and without the centric fragment).

Among the 32 self-compatible mutants six plants, however, responded erratically to the test-crosses and could not be classified with accuracy. Except for the self-compatible individuals (including the plants with erratic behaviour), all progenies constantly expressed self-incompatibility. The self-incompatible individuals were, in most cases, detected in clusters, that is to say within few fruits (fig. 1), and segregated normally in a $1: 2: 1$ ratio for $S_{2} S_{2}: S_{2} S_{3}: S_{3} S_{3}$ (31:60:28).

In the 26 stable self-compatible mutants the self-compatibility character only involved the capacity of the pollen to grow through normally incompatible styles and is equated here to the pollen-part ( $\mathrm{pp}$ ) mutations described in detail by Brewbaker and Natarajan (1960) and Pandey (1965, 1967b, $1969 c)$.

\section{(a) Description of the self-compatible mutants}

As can be seen in table 3, five of the 26 stable self-compatible mutants were $S$-homozygous (that is to say reciprocally compatible with the original $S_{2} S_{3}$ mother clone, but incompatible as females, with one of the homozygous tester stocks). The test-crosses with homozygous tester lines revealed that

TABLE 3

Classification of $\mathrm{S}$-genotypes in the progeny of the cross $\mathrm{S}_{2} \mathrm{~S}_{3}$ o $\times$ irradiated $\mathrm{S}_{2} \mathrm{~S}_{3}{ }_{0}$

\begin{tabular}{|c|c|c|c|c|c|c|c|c|}
\hline & \multirow{3}{*}{$\begin{array}{l}\text { Dose } \\
\text { (rad) }\end{array}$} & \multirow{3}{*}{$\begin{array}{l}\text { No. of } \\
\text { plants } \\
\text { tested }\end{array}$} & \multicolumn{6}{|c|}{$S$-genotypes } \\
\hline & & & \multirow[b]{2}{*}{$S_{2} S_{2}$} & \multirow[b]{2}{*}{$S_{2} S_{3}$} & \multirow[b]{2}{*}{$S_{3} S_{3}$} & \multicolumn{2}{|c|}{$\overbrace{}^{p p}$} & \multirow[b]{2}{*}{ sp } \\
\hline & & & & & & HOM & HET & \\
\hline \multirow[t]{2}{*}{ Control } & - & 36 & 9 & 19 & 6 & 1 & 1 & - \\
\hline & 300 & 2 & - & - & 1 & - & $1 *$ & - \\
\hline \multirow[t]{2}{*}{$\mathrm{X}$-rays } & 600 & 25 & 2 & 9 & 10 & - & $1^{*}$ & $3 * *$ \\
\hline & $(825$ & 9 & - & - & - & 2 & 7 & - \\
\hline \multirow{3}{*}{ Fast neutrons } & 50 & 24 & 4 & 8 & 5 & 1 & 6 & - \\
\hline & $\{175$ & 6 & - & - & - & - & 6 & - \\
\hline & 300 & 49 & 16 & 24 & 6 & 1 & 1 & $1 * *$ \\
\hline
\end{tabular}

four of these plants were $S_{3}$ homozygous $\left(\mathrm{pp}-\mathrm{HOM}_{3}\right.$ ), while the fifth was homozygous for $S_{2}$ (pp-HOM $\mathrm{M}_{2}$ ). The remaining 21 self-compatible plants were cross-compatible as staminate parents with the original clone and with the two tester stocks, but rejected, as pistillate partners, $S_{2}$ and $S_{3}$ pollen. These plants are $S$-heterozygotes which carry a pollen-part mutation (pp-HET).

The five pp-HOM plants (four pp-HOM ${ }_{3}$ and one pp-HOM$M_{2}$ ) and 19 of the pp-HET plants were analysed cytologically (table 4). Eleven mutants displayed a centric fragment in addition to the normal chromosome complement (Brewbaker and Emery, 1960; Brewbaker and Natarajan, 1960; Lewis, 1961 ; Pandey, 1965). Among these 11 mutants, eight were pp-HET, 
two were pp- $\mathrm{HOM}_{3}$ and one was pp- $\mathrm{HOM}_{2}$. The ratio of fragment to nonfragment self-compatibility mutations approximated one to one in both the control and in the irradiation series.

TABLE 4

Description (cytology and S-genotype) of the self-compatible pollen-part mutants

\begin{tabular}{|c|c|c|c|c|c|c|c|c|}
\hline \multirow[b]{2}{*}{$\begin{array}{c}\text { Mutants } \\
\text { considered }\end{array}$} & \multirow[b]{2}{*}{$\begin{array}{l}\text { No. of mutants } \\
\text { analysed }\end{array}$} & \multicolumn{2}{|c|}{$\begin{array}{c}\text { Control } \\
\text { No. of plants }\end{array}$} & \multicolumn{2}{|c|}{$\begin{array}{c}\text { X-rays } \\
\text { No. of plants }\end{array}$} & \multicolumn{2}{|c|}{$\begin{array}{l}\text { Fast neutrons } \\
\text { No. of plants }\end{array}$} & \multirow[t]{2}{*}{ Total } \\
\hline & & + & - & + & - & + & - & \\
\hline pp-HET & 19 & & 1 & 2 & 4 & 6 & 6 & \\
\hline $\mathrm{pp}-\mathrm{HOM}_{2}$ & 1 & & & 1 & & & & \\
\hline $\mathrm{pp}-\mathrm{HOM}_{3}$ & 4 & 1 & & & 1 & 1 & 1 & \\
\hline No. of plants & th a fragment & 1 & & 3 & & 7 & & 11 \\
\hline No. of plants & thout a fragment & & 1 & & 5 & & 7 & 13 \\
\hline
\end{tabular}

\section{(b) Description of plants with erratic behaviour}

Six plants responded erratically to the test-crosses (table 3). An analysis of the selfed progenies of these plants revealed that a pollen-part mutation was segregating in two progenies. The situation was not clear in the other four cases but it appeared, nevertheless, that some of the pollen produced by the erratic mutants carried a mutation for the activity-part of the style.

\section{(iv) Mutation rates}

The mutation rates (number of self-compatible individuals per pollination) are shown in table 2 . In the case of X-irradiation the number of pollen-part mutants per pollination increased with dose. With fast neutrons these values were much higher than after $\mathrm{X}$-rays. There is, however, with fast neutrons, no clear relationship between doses and responses. As a whole it can be said that the highest dose of X-rays and all doses of fast neutrons increased the number of pollen-part mutants per pollination by a factor of four or more as compared to the spontaneous mutation rate in the control. Stylar-part mutants were only detected at two doses (600 rad X-rays; 300 rad fast neutrons).

\section{Discussion}

\section{(i) The relative effectiveness of fast neutrons and $X$-rays}

(a) Irradiation effects on pollen fertility, fruit set and seed set

The decrease of pollen fertility with increasing doses in both the fast neutrons and the X-rays series was of course expected from the work of many different authors (e.g. Yamakawa and Sparrow, 1965; Yamakawa, 1966; van Gastel and de Nettancourt, 1974) and had been predicted from the preliminary experiments carried out for determining the doses of X-rays and fast neutrons which induced comparable amounts of pollen abortion. Unexpected, however, was the increase in fruit set and seed set (particularly striking after fast neutron irradiation). Such an increase has been previously 
reported after chronic exposure of self-incompatible species (de Nettancourt and Ecochard, 1968; van Gastel and de Nettancourt, 1974) and attributed to an inhibition of floral abscission or to an alteration of metabolic activity in the style but was never found to occur to the same extent after acute treatment of PMC's. Since all pollinations were carried out on unirradiated plants the stimulation of fruit set and seed set resulted from a modification induced in the pollen. This modification, judging from the relatively low number of $S$-mutations recorded in the progeny tests, did not derive, in many instances, from permanent genetic changes of the $S$-alleles.

It is most remarkable in this connection, that practically all permanent $S$-mutations were detected in the progeny of fruits which contained only few seeds, whereas most of the non-mutated offspring derived from fruits containing high numbers of seeds. Since revertible mutations can hardly be expected to have occurred in such high frequencies it is possible that the radiation treatment and/or certain physiological changes in the floral environment induced a kind of pseudo-compatibility which has probably nothing to do with mutations at the $S$-locus. Of course, such a conclusion does not necessarily hold for those non-mutated individuals which were recovered in the progenies arising from fruits containing only few seeds. It is most likely that revertible mutations, as defined by Lewis (1951), are responsible for the occurrence of these plants.

\section{(b) The efficiency of fast neutrons for inducing self-compatibility mutations}

The mutation rates were always higher after fast neutron irradiation than in the X-ray series. Although no relationship could be established between neutron doses and mutation rates, it is clear that the RBE of fast neutrons greatly exceeds one. Whether or not this greater effectiveness of fast neutron irradiation is of any practical value in plant breeding is, however, a debatable point because mutation rates need not necessarily be expressed in terms of mutations per pollination but could also be defined, for practical purposes, as the number of mutant plants per fruit or per progeny plant. In such a case the irregular distribution of fruits and seeds distort the mutation rates to an extent which ceases to reveal any consistent superiority of fast neutron irradiation. The best advice which may be given to the plant breeder, who is anxious to recover a maximum of self-compatible mutants through a minimum of labour and of greenhouse space is to use fast neutron irradiation (which produces the highest number of mutations per pollination) and to score for mutations only among those progenies arising from fruits with low seed numbers (less than 15 seeds per fruit).

\section{(c) Types of permanent self-compatibility mutations induced by $X$-rays and fast neutrons}

As could be expected from the fact that only pollen grains are submitted to the screening system provided by an incompatible style, all the 26 permanent self-compatibility mutations recorded in the progeny tests were pollenpart mutations.

Among the 24 plants analysed cytologically, 11 displayed a centric fragment whereas the remaining plants did not exhibit any visible addition or clear modification in their karyotypes. The latter type of mutations have been suspected to occur after irradiation by Lewis (1961) who, on the basis of segregation data, concluded that the induced self-compatibility character 
in pollen-part mutants of Oenothera did not depend upon the presence of additional fragments in the pollen grains, but it is to our knowledge the first time that they are demonstrated to be induced in such frequency.

The exact nature of these two classes (with and without a centric fragment) of self-compatibility mutations is a matter of controversy. The mutations associated with the presence of a centric fragment have been explained by Brewbaker and Natarajan (1960) on the basis of competitive interaction between two different $S$-alleles, one on the fragment and the other in the normal genome of the haploid pollen grain. Such a view has been challenged by Pandey (1967b) who considered that the essential role of the fragment is to complement an otherwise lethal pollen-part mutation at the $S$-locus. This last interpretation has been confirmed at our laboratory (van Gastel, in preparation) by several tests which corroborate Pandey's finding that self-compatible $S$-homozygous individuals can be recovered from the inbred progeny of heterozygous self-compatible mutants with a centric fragment which, according to the competition theory, should only produce $S$-heterozygous offspring. With regard to the class of self-compatible mutants which do not display a centric fragment, two different explanations have been advanced in the past. Lewis (1961) suggested that these mutants carried a genuine $S$-mutation, whereas Pandey (1967b) postulated that they integrated an $S$-bearing duplication within the normal $S$-bearing chromosome, which complemented an otherwise lethal $S$-mutation. Pandey essentially based his theory upon the fact that he recovered, in the progeny of a pollen-part mutant without the centric fragment, individuals which displayed three $S$-specificities in the style. Preliminary work at our laboratory shows (van Gastel, in preparation) that such individuals do indeed appear regularly in the progenies of self-compatible mutants without a centric fragment. It therefore appears that complementation is indeed the basis of most induced self-compatibility mutations in Nicotiana alata and that the phenomenon can occur through integrated duplications or via centric fragments. These two cytological events are apparently induced in equal proportions by X-rays and fast neutrons and there does not seem to be, in this respect, any difference in the mutation spectra of the two mutagens.

The high frequency (about 50 per cent) of pollen-part mutants without a centric fragment which was recorded in the present study is at variance with the data of Pandey (1967b) who found, out of 63 mutants analysed cytologically, only one mutant of this class. This quantitative difference in results may perhaps be attributed to the higher dose $(1000 \mathrm{rad})$ used by Pandey or to variations in the genetic constitution of the Nicotiana lines, which were used as test material. Since the two classes of mutants were equally distributed in the present work, among the X-rays and the fast neutron series, it is obvious that the discrepancy with the data of Pandey cannot be attributed to a specific property of fast neutron irradiation.

\section{(d) Erratic mutants}

The fact that four erratic stylar-part mutants were found shows, as in the experiments of Pandey (1967b), that it is also possible to mutate the stylar component of the self-incompatibility reaction. Since $S$-homozygotes with a stylar-part mutation in one of the two $S$-bearing chromosomes will not express a self-compatible phenotype, it is probable that larger numbers of stylar-mutants were present in the progenies. 
Stylar-part mutations, however, do not confer self-compatibility to the pollen grains, therefore these mutations were associated with a phenomenon which enabled the pollen to overcome the incompatibility barrier. Since the stylar-part mutants were only detected in progenies where a high number of non-mutants were present, it is proposed that such stylar-part mutant pollen grains were able to fertilise the eggs as a result of pseudo-compatibility.

\section{(e) Constructive mutations}

If one assumes that constructive mutations, that is to say generation of new $S$-alleles, do not first restrict their appearance to the style, but are also expressed in the pollen (for a discussion, see de Nettancourt et al., 1971) our results show that fast neutrons are as ineffective as X-rays for reconstructing within the $S$-gene and promoting the formation of functional alleles.

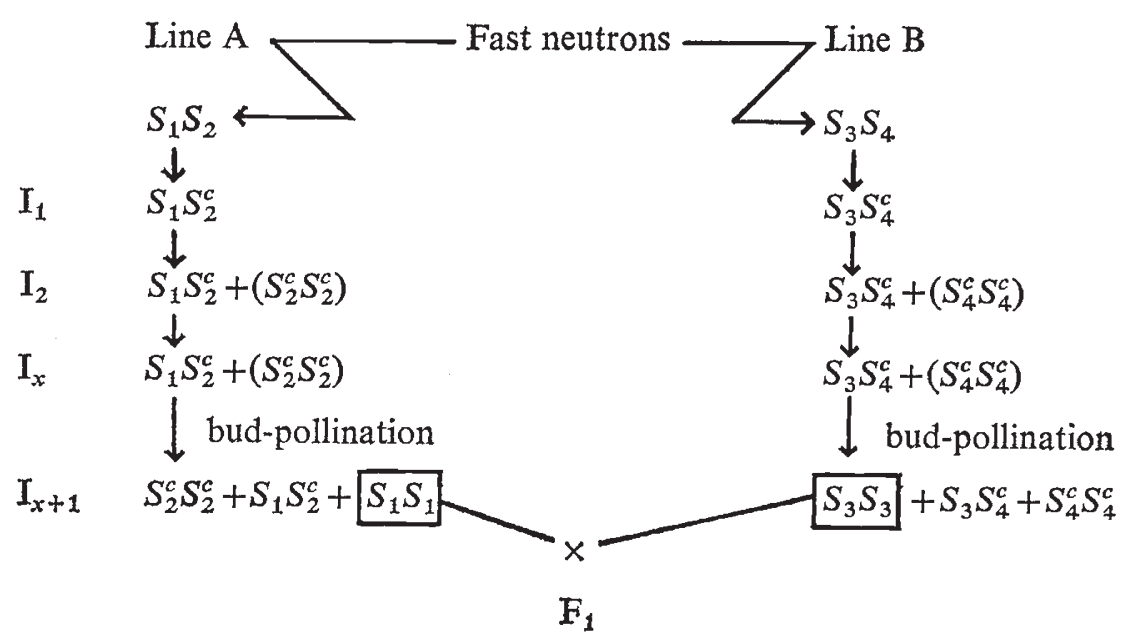

FIG. 2.-Inbreeding scheme of self-compatible $S$-heterozygotes and production of selfincompatible $S$-homozygotes for constitution of $F_{1}$ hybrid seeds. $S^{c}=$ permanent mutation conferring compatibility to the pollen which carries it. If the self-compatibility character originates from a competition effect mediated by a free centric fragment, the inbred progenies will consist of self-compatible $S$-heterozygotes only.

\section{(ii) Implication for plant breeding}

The utility for the plant breeder of induced or spontaneous selfcompatibility mutations of the same type as those which were obtained in the present study has been reviewed by de Nettancourt (1972). Such mutations can serve the three following purposes:

1. The production in homozygous condition of valuable combinations of recessive genes and the elimination of sub-lethal combinations of recessive genes.

2. The maintenance of a high level of self-fertilisation (within clone) in fruit crops.

3. The production of inbred lines with superior combining ability for the production of synthetic varieties and of $F_{1}$ hybrid seeds. 
Concerning the last possibility of application (production of inbred lines with superior combining ability) it has always been taken for granted that the self-compatibility character to be used should be of a temporary nature and ought not to involve the participation of a permanent mutation at the $S$-locus. However, we would like to point out a possible use of permanent selfcompatible mutants for the production of $F_{1}$ hybrid seed. The system we propose is outlined in fig. 2 and replaces almost entirely the low seed yielding and tedious procedure of bud-pollination by the simple selfpollination of self-compatible $S$-heterozygous inbred plants.

Such heterozygous plants only need to be selfed repeatedly during several generations and their progenies sorted out for $S$-heterozygosity at each generation until the desired number of inbreeding generations has been reached. Selected $S$-heterozygotes are then submitted to a last generation of selfing (e.g. through bud-pollination) and their progenies screened for self-incompatible inbred lines, with superior combining ability.

Such a scheme is simple and will not even require any test-crossing for detection of $S$-heterozygotes if the self-compatibility character is based upon the presence of a competition fragment which only leads to the formation of $S$-heterozygotes.

Acknowledgments.-The authors wish to thank Prof. J. H. van der Veen, Dr J. G. Th. Hermsen, Dr A. Ringoet, Dr C. Broertjes and Dr G. Bredemeijer for critical reading of the manuscript. Thanks are also due to Mr P. Dijkhuis and Miss J. Gootjes for their very valuable technical assistance. The cytological assistance of $\mathrm{Mr}$ G. Merkx is gratefully acknowledged.

\section{REFERENCES}

BREWBAKER, J. L., AND EMERY, G. c. 1960. Incompatibility allele mutations. Genetics, 45, 978.

BREWBAKER, J. L., AND Natarajan, A. T. 1960. Centric fragments and pollen-part mutation of incompatibility alleles in Petunia. Genetics, 45, 699-704.

BREWBAKER, J. L., AND SHAPIRO, N. 1959. Homozygosity and $S$ gene mutation. Nature, 183, 1209-1210.

CONTANT, R. B., DEVREUX, M., ECOCHARD, R. M., MONTI, L. M., NETTANCOURT, D. DE, SCARASCIA MUGNOZZA, G. T., AND VERKERK, K. 1971. Radiogenetic effects of gamma- and fast neutron irradiation on different ontogenetic stages of the tomato. Radiat. Bot., 11, 119-136.

GASTEL, A. J. G. VAN, AND DE NETTANCOURT, D. 1974. The effects of different mutagens on self-incompatibility in Nicotiana alata Link and Otto. I. Chronic gamma irradiation. Radiat. Bot., 14, 43-50.

hoffmann, M. 1971. Induktion und Analyse von selbstkompatiblen Mutanten bei $L y c o-$ persicon peruvianum (L.) Mill. I. Analyse der selbstkompatiblen Mutanten. Biol. Zbl. $90,33-41$.

HOGENBOOM, N. G. 1972. Breaking breeding barriers in Lycopersicon. 2. Breakdown of selfincompatibility in L. peruvianum (L.) Mill. Euphytica, 21, 228-243.

LEWIS, D. 1946. Useful X-ray mutations in plants. Nature, 158, 519-520.

LEWIS, D. 1948. Structure of the incompatibility gene. I. Spontaneous mutation rate. Heredity, 2, 219-236.

LEWIS, D. 1949. Structure of the incompatibility gene. II. Induced mutation rate. Heredity, 3, 339-355.

LEWIS, D. 1951. Structure of the incompatibility gene. III. Types of spontaneous and induced mutations. Heredity, 5, 399-414.

LEWIS, D. 1961. Chromosome fragments and mutation of the incompatiblity gene. Nature, $190,990-991$.

LUNDQVist, U., AND WETTSTEIN, D. VON 1962. Induction of eceriferum mutants in barley by ionizing radiations and chemical mutagens. Hereditas, 48, 342-362. 
NETTANCOURT, D. DE. 1972. Self-incompatibility in basic and applied researches with higher plants. Genet. agr., 26, 163-216.

NETTANCOURT, D. DE, AND ECOCHARD, R. 1968. Effects of chronic irradiation upon a selfincompatible clone of Lycopersicon peruvianum. Theoret. Appl. Genet., 28, 289-293.

NETTANCOURT, D. DE, ECOCHARD, R., PERQUIN, M. D. G., DRIFT, T. VAN DER, AND WESTERHOF, M. 1971. The generation of new $S$ alleles at the incompatibility locus of Lycopersicon peruvianum Mill. Theoret. Appl. Genet., 41, 120-129.

PANDEY, K. K. 1956. Mutations of self-incompatibility alleles in Trifolium pratense and T. repens. Genetics, 41, 327-343.

PANDEY, K. K. 1964. Elements of the S-gene complex. Genet. Res., 5, 397-409.

PANDEY, K. K. 1965. Centric chromosome fragments and pollen-part mutation of the incompatibility gene in Nicotiana alata. Nature, 206, 792-795.

PANDEY, K. K. 1967a. S gene polymorphism in Nicotiana. Genet. Res., 10, 251-259.

PANDEY, K. K. 1967b. Elements of the Sugene complex. II. Mutation and complementation at the $S_{\mathbf{I}}$ locus in Nicotiana alata. Heredity, 22, 255-284.

PANDEY, K. K. 1969a. Elements of the $S$-gene complex. V. Interspecific cross-compatibility relationship and theory of the evolution of the $S$ complex. Genetica, 40, 447-474.

PANDEY, K. K. 1969b. Elements of the $S$-gene complex. IV. $S$ allele polymorphism in Nicotiana species. Heredity, 24, 601-619.

PANDEY, K. K. 1969c. X-irradiation induced $S$-gene mutations, accumulated centric chromosome fragments, and evolution of B-chromosomes. In: FAO/IAEA Symposium on Induced Mutations in Plants, 621-635. IAEA, Vienna.

PANDEY, K. K. 1970a. Elements of the $S$-gene complex. VI. Mutations of the self-incompatibility gene, pseudo-compatibility and origin of new self-incompatibility alleles. Genetica, 41, 477-516.

PANDEY, K. K. $1970 b$. New self-incompatibility alleles produced through inbreeding. Nature, 227, 689-690.

YAMAKAWA, K. 1966. Relative radiosensitivities of three developmental stages, i.e. floral development, gametogenesis, and embryogenesis under chronic gamma irradiation. Gamma Field Symp., No. 5, 91-122. Institute of Radiation Breeding, Japan.

YAMAKAWA, K., AND SPARROW, A. H. 1965. Correlation of interphase chromosome volume and reduction of viable seed set by chronic irradiation of 21 cultivated plants during reproductive stages. Radiat. Bot., 5, 557-566. 